\title{
Urodynamics in a Community-dwelling Population of Females 80 Years or Older. Which Motive? Which Diagnosis?
}

\author{
Françoise A. Valentini, Gilberte Robain, Brigitte G. Marti, Pierre P. Nelson
}

ER6 (FAV, GR, PPN), Université Pierre et Marie Curie (Paris VI), Paris, France, and Department of Physical Medicine and Rehabilitation (FAV, GR, BGM), Hôpital Charles Foix, Ivry-sur-Seine, France

\begin{abstract}
Purpose: To determine why community-dwelling women aged 80 years or over were referred for urodynamic evaluation despite their advanced age and which urodynamic diagnosis was made.

Materials and Methods: One hundred consecutive females (80-93 years) were referred to our urodynamics outpatient clinic for evaluation of lower urinary tract symptoms (LUTS) between 2005 and 2008. Clinical evaluation comprised of a previous history of LUTS, previous medical history of neurological disease or dementia, pelvic floor dysfunction or prior pelvic surgery. Exclusion criteria were complete retention and severe dementia involving failure to understand simple instructions. Assessed items were results of uroflows (free flow and intubated flow), cystometry and urethral pressure profilometry, and final urodynamic diagnosis.

Results: The main complaint evoked by the patients was incontinence $(65.0 \%)$ of which $61.5 \%$ was "complicated" and urgency was reported by $70.0 \%$.

Interpretable free flow at arrival was very low (44.0\%). Prevalence of detrusor overactivity was high, found in 45 patients of whom 16 had detrusor hyperactivity with impaired detrusor contractility. Detrusor overactivity and urgency were strongly associated $(\mathrm{p}=0.004)$. Twenty-five patients had intrinsic sphincteric deficiency alone and 15 detrusor underactivity.

Conclusion: In this particular community-dwelling with an elderly female population, urodynamics is easily feasible. Incontinence, mainly "complicated" is the more frequent complaint and urgency the more frequent symptom. Urodynamic diagnosis underlines the high incidence of detrusor overactivity as well as impaired detrusor function.
\end{abstract}

Key words: ageing; women; bladder outlet obstruction; urodynamics

Int Braz J Urol. 2010; 36: 218-24

\section{INTRODUCTION}

Demographic trends indicate that the most rapidly growing adult population older than 65 years is the sub-group older than 85 . Some troublesome problems are reported in the elderly primarily due to a change in lower urinary tract (LUT) function. The evaluation of LUT dysfunction is based on urodynamic investigation which is considered the gold standard. In fact, the use of urodynamics remains debatable, as it is invasive, expensive, time consuming, and frequently it is unhelpful to achieve a final diagnosis. The place of urodynamics in the elderly has been mainly discussed concerning incontinent patients and in the frail and elderly living in a long term care residence $(1,2)$ but less studied 
in the community-dwelling elderly (3). Guidelines suggest to carry out urodynamics in the elderly after failure of conservative treatment or surgery, and do not recommend urodynamics for frail elders. Often, this procedure is not easy to put into practice as in the case of our urodynamics outpatients clinic where evaluations are performed only when requested by a general practitioner, gynecologist or urologist.

In recent years, more and more elderly females have been referred for evaluation of LUT dysfunction. The major part of this population consists of community-dwelling women who live at home, perform daily tasks, take an active part in society and play sports well into old age. Therefore, the remaining question is the diagnosis of frailty in order to take into account the guidelines. Distinction between ageing, disability and frailty is not clear and the objective measurement of frailty remains to be discussed $(4,5)$. When considering research findings, the prevalence of frailty ranges from $33 \%$ to $88 \%$ according to the criteria employed (6). Multiple systems must be involved in the frailty definition: sarcopenia, osteopenia, nutritional changes, factors of illness. It has been suggested that older persons who retain the capacity to improve (even a small increase in their gait speed) are therefore not frail (5).

Prevalence of lower urinary tract symptoms (LUTS) and LUT dysfunction increases significantly with ageing. Most urinary problems are multifactorial in origin and are not only the result of the LUT changes with aging (7). Age related changes in the female LUT involve both bladder, impaired contractility or overactivity, and urethra, decreased urethral closure pressure and urogenital atrophy. Some studies have been conducted in order to evaluate the effect of age on the LUT function (8-12). In fact, these studies seldom concerned the oldest subgroup and were mainly devoted to the role and effects of detrusor overactivity $(8,11,12)$. Taking into account these limitations, our objective was to assess a sizeable population of community-dwelling women, aged 80 years or more, referred for urodynamics in our outpatients' clinic in order to answer to the following questions: why is urodynamics prescribed, what are the patient complaints, what are the urodynamic findings and the urodynamic diagnosis and finally, is urodynamics able to help the physician to achieve a better management of LUTS?

\section{MATERIALS AND METHODS}

This was a retrospective study. Among 848 women of all ages referred to our urodynamics outpatient clinic between January 2005 and March 2008, $100(11.8 \%)$ aged 80 years or more (mean age 83.2 years; range 80-93 years) were community-dwelling and able to perform everyday tasks.

This study was conducted in accordance with the declaration of Helsinki. According to the local practice of our Ethics Committee, there is no formal Institutional Review Board approval required for retrospective studies.

Assessment by a physician included detailed medical history and usual medication, physical examination (including neurological and cognitive testing). All patients completed a 2- or 3-day bladder diary and had a urine dipstick test.

Specific evaluation comprised of a history of LUTS being the major complaint in cases of concomitant LUTS, previous medical history of neurological disease (stroke, multiple sclerosis, lumbar injury etc.) or dementia, pelvic floor dysfunction and previous pelvic surgery. Exclusion criteria were complete retention, severe dementia involving failure to understand simple orders or a Mini-Mental State score $<20$. One patient with spinal cord injury was excluded from the study.

Quality of life was assessed using the International Consultation on Incontinence QuestionnaireShort Form (ICIQ-SF) for incontinent patients and the visual analog scale (VAS) for continent patients.

Urodynamics was performed according to Good Urodynamic Practices (13) with a Laborie's Dorado ${ }^{\circledR}$ unit. Detailed urodynamic testing included: 1) an initial free uroflow (FF1), 2) a cystometry in the seated position at the medium filling rate of $50 \mathrm{~mL} /$ min with normal saline at room temperature (triplelumen urethral catheter $10 \mathrm{~F}$ for 67 patients and $7 \mathrm{~F}$ for 33 patients) and intubated flow (IF), 3) urethral pressure profilometry (UPP) in supine position, empty bladder (before the cystometry) and 200-250 mL filling if incontinent, and 4) a second free uroflow (FF2) if bladder was filled for UPP. 
No routine provocative maneuver for detrusor overactivity (DO) was performed during cystometry but coughs were used as quality control of pressure recordings (13).

Studied items were results from uroflows (FF1, FF2 and IF), filling cystometry and UPP, and final urodynamic diagnosis. To be interpretable, a uroflow had to have a urinated volume $>100 \mathrm{~mL}$.

Data are presented as mean \pm SD and range. The Wilcoxon signed-rank test was used for comparison of related samples and the Chi 2 test to compare unrelated samples with $\mathrm{p}<0.05$ considered significant. Statistical analyses were performed using SAS, version 5.0 (SAS Institute, Inc., Cary, NC).

\section{RESULTS}

\section{Motive for Urodynamics}

Patients' main complaints are summarized in Table-1. Incontinence was the main complaint: 22 urge, 32 mixed and 11 stress. Forty patients had previously received treatment (chemical or surgical) for incontinence in middle age or later as well as for recurrent incontinence or developed urgency. Among these patients, 12 had anticholinergic treatment failure for DO. Other complaints were 16 frequency ( $\geq 8$ voids per 24 hours), 12 dysuria (low stream or hesitancy or straining) or incomplete retention and
1 cystitis (recurrent urinary tract infection and pain during voiding); 6 patients with pelvic organ prolapse had a pre-operative evaluation.

Incidence of incontinence (stress, urge and mixed) was $65.0 \%$ close to that of the symptom urgency (urge or mixed incontinence, and frequency) which was evoked by $70.0 \%$ of this elderly population.

ICIQ-SF score was $12 \pm 4$ (maximum 21) and VAS score $4.2 \pm 2.5$ (maximum 10).

\section{Previous Medical History}

Previous medical history of disease and/or pelvic surgery was obtained by detailed questioning which is summarized in Table-2.

\section{Feasibility of FF and IF}

A significant result was the low percentage $(44.0 \%)$ of interpretable free flow (FF) on arrival (FF1) compared to the percentages of interpretable IF and FF2 (Table-3).

\section{Maximum Cystometric Capacity (MCC)}

Patients able to perform an IF (voided volume $=209 \pm 135 \mathrm{~mL})$ had a MCC of $337 \pm 150 \mathrm{~mL}(\mathrm{p}<$ $0.001)$.

Table 1 - Patient main complaint vs. urodynamic diagnosis.

\begin{tabular}{|c|c|c|c|c|c|c|c|}
\hline \multirow{2}{*}{\multicolumn{2}{|c|}{ Patient Main Complaint }} & \multicolumn{5}{|c|}{ Urodynamic Diagnosis } & \multirow[t]{2}{*}{ Number of Women } \\
\hline & & DO & ISD & DU & LBC & $\mathbf{N}$ & \\
\hline \multirow{3}{*}{ Incontinence } & Stress & 2 & 7 & 0 & 1 & 1 & 11 \\
\hline & Urge & 16 & 4 & 0 & 0 & 2 & 22 \\
\hline & Mixed & 15 & 10 & 2 & 2 & 3 & 32 \\
\hline \multicolumn{2}{|c|}{ Incomplete retention or dysuria } & 2 & 0 & 10 & 0 & 0 & 12 \\
\hline \multicolumn{2}{|c|}{ Preoperative for POP } & 3 & 1 & 1 & 0 & 1 & 6 \\
\hline \multicolumn{2}{|c|}{ Frequency } & 7 & 2 & 2 & 2 & 3 & 16 \\
\hline \multicolumn{2}{|c|}{ Cystitis } & 0 & 1 & 0 & 0 & 0 & 1 \\
\hline \multicolumn{2}{|c|}{ Number of women } & 45 & 25 & 15 & 5 & 10 & 100 \\
\hline
\end{tabular}

$D O=$ detrusor overactivity; ISD = intrinsic sphincteric deficiency; $D U=$ detrusor underactivity; LBC = low bladder compliance; $N=$ normal urodynamic data $; P O P=$ pelvic organ prolapse. 
Table 2 - Previous medical history of the studied population.

\begin{tabular}{lc}
\hline Previous History & $\begin{array}{c}\text { Number of } \\
\text { Women }\end{array}$ \\
\hline Neurological disease & 23 \\
Cognitive impairment & 12 \\
$\quad$ (Mini-Mental State $\geq 20)$ & \\
Pelvic surgery & \\
$\quad$ pelvic organ prolapse & 16 \\
hysterectomy & 23 \\
TVT & 8 \\
sling & 6 \\
$\quad$ others & 4 \\
Other diseases & \\
muscle-skeletal & 29 \\
cardio-vascular & 57 \\
depression & 15 \\
diabetes mellitus & 9 \\
\hline
\end{tabular}

$T V T=$ Tension-free vaginal tape.

\section{Cystometry}

Detrusor overactivity (involuntary detrusor contractions during the filling phase: DO) was found in 45 patients $(45 \%)$ of whom $15(33.3 \%)$ had a previous history of neurological disease.

In this population $16 / 45(35 \%)$ had detrusor hyperactivity with impaired contractility (detrusor hyperactivity with incomplete bladder emptying leading to major post void residual (PVR) (detrusor hyperactivity with impaired contractility (DHIC).

Rhythmic rectal contractions (RRCs) were observed in 29 patients of whom $9(31.0 \%)$ had a history of neurological disease. Among these 29 women, $18(62 \%)$ had DO (7 with a history of neurological disease).

\section{Intubated Flow}

Among the 69 IF obtained, only $50(72.5 \%)$ were interpretable. Voiding parameters were: maxi- mum flow rate $\mathrm{Q}_{\max }=11 \pm 5 \mathrm{~mL} / \mathrm{s}[2-30 \mathrm{~mL} / \mathrm{s}]$, detrusor pressure at opening $\mathrm{p}_{\text {det.op }}=15 \pm 10 \mathrm{~cm} \mathrm{H}_{2} \mathrm{O}[0-47$ $\left.\mathrm{cm} \mathrm{H}_{2} \mathrm{O}\right]$ and detrusor pressure at $\mathrm{Q}_{\max } \mathrm{p}_{\text {det.Qmax }}=19 \pm$ $11 \mathrm{~cm} \mathrm{H}_{2} \mathrm{O}\left[5-48 \mathrm{~cm} \mathrm{H}_{2} \mathrm{O}\right](\mathrm{p}<0.0001)$, and voiding time $\mathrm{t}_{\mathrm{void}}=52 \pm 46 \mathrm{~s}[7-300 \mathrm{~s}]$.

\section{Urethral Pressure Profilometry}

Maximum urethral closure pressure (MUCP) was $44 \pm 22 \mathrm{~cm} \mathrm{H}_{2} \mathrm{O}$ bladder empty and $35 \pm 17 \mathrm{~cm}$ $\mathrm{H}_{2} \mathrm{O}$ bladder filled $(\mathrm{p}=0.01)$. The "theoretical" value for the studied age range was $30-40 \mathrm{~cm} \mathrm{H}_{2} \mathrm{O}$ (14). It is important to note that between 47 patients who had at least one MUCP value (bladder empty or filled) $\leq 30$ $\mathrm{cm} \mathrm{H}_{2} \mathrm{O}$, only 25 had intrinsic sphincteric deficiency (ISD) (isolated low MUCP and urodynamic stress incontinence) as a final urodynamic diagnosis.

\section{Final Urodynamic Diagnosis}

DO was the main diagnosis, found in 45 patients of whom 16 had DHIC; ISD concerned only 25 patients, detrusor underactivity (defined as absence of detrusor contraction during voiding and large PVR) was found in 15 , low bladder compliance $\left(\Delta \mathrm{V} / \Delta \mathrm{p}_{\text {ves }}\right.$ less than $20 \mathrm{~mL} / \mathrm{cm} \mathrm{H}_{2} \mathrm{O}$ ) in 5 and normal urodynamic data in 10. In the population for which ISD was not predominant, 15 patients had DO, 5 detrusor underactivity and 2 low bladder compliance.

The Table- 1 shows the distribution between main patient complaint and urodynamic diagnosis.

Complaint of urgency (symptom) was found to have a sensitivity of $54.3 \%$, a specificity of $76.7 \%$ and a predictive positive value of $84.4 \%$ for the detection of DO; complaint of stress or mixed incontinence was found to have a sensitivity of $39.5 \%$, a specificity of $85.9 \%$ and a predictive positive value of $68.0 \%$ for the detection of ISD.

\section{COMMENTS}

A major part (40\%) of the studied population had failure of conservative treatment or recurrence of incontinence after surgical cure. These women 
Urodynamics for Community-dwelling Women Aged $\geq 80$ Years

Table 3 - Feasibility of free and intubated flows during the urodynamic session.

\begin{tabular}{|c|c|c|c|c|c|c|}
\hline \multirow[t]{2}{*}{ Flow } & \multicolumn{2}{|c|}{ Obtained } & \multicolumn{2}{|c|}{$\begin{array}{l}\text { Interpretable } \\
\left(\mathrm{V}_{\mathrm{u}}>100 \mathrm{~mL}\right)\end{array}$} & \multirow[t]{2}{*}{$\begin{array}{l}\text { Bell Shaped } \\
\text { Curves }\end{array}$} & \multirow[t]{2}{*}{$\begin{array}{l}\text { Not Obtained (n.o.) } \\
\text { Not Performed (n.p.) }\end{array}$} \\
\hline & nbr & $\mathbf{V}_{\mathbf{u}}(\mathrm{mL})$ & nbr & $\mathbf{V}_{\mathrm{u}}(\mathrm{mL})$ & & \\
\hline FF1 & 75 & $92 \pm 105$ & $33(44.0 \%)$ & $158 \pm 113$ & $20(60 \%)$ & 16 (n.o.) 9 (n.p.) \\
\hline IF & 69 & $209 \pm 135$ & $50(72.5 \%)$ & $263 \pm 114$ & $21(42 \%)$ & 31 (n.o.) \\
\hline FF2 & 69 & $256 \pm 116$ & $63(91.3 \%)$ & $268 \pm 109$ & $27(43 \%)$ & 31 (n.p.) \\
\hline
\end{tabular}

$F F=$ free flow; $I F=$ intubated flow, $n b r=$ number

desired further attempts to correct or manage their incontinence. This condition implies urodynamics for a detailed and objective diagnosis. The other $60 \%$ agree to urodynamics as their LUT dysfunction has developed for many years (up to 20 years etc.) and has become a cause of decreased quality of life, or is an acute problem (e.g. incomplete retention after knee or hip surgery).

It is well known that the prevalence of urinary incontinence increases with ageing. In the age range higher than 80 years, the reported rate of incontinence is $35 \%$ for community-dwelling women in a questionnaire survey (15) and $82 \%$ for institutionalized women (2). We found an intermediate rate of $65 \%$ probably due to our recruitment, i.e. women with LUTS whose physicians requested urodynamics. It has been reported that urgency and urge incontinence increase with aging, while if stress incontinence is the main complaint among the women between 25 and 49 years of age it remains a constant complaint in women over 80 (15). In our population, urge and mixed incontinence were the main causes of leakage $(54 \%)$ and pure stress urinary incontinence was moderately observed (11\%). In contrast, urgency appears as the main symptom as it associates frequency and accounts for $70 \%$ (as opposed to $42.0 \%$ in the group of 748 female patients under age 80 explored during the same period in our laboratory). Urgency is a symptom related to bladder overactivity while DO is only a urodynamic diagnosis.

Acute complaint was only incomplete retention after hip or knee surgery and mainly secondary to hip arthroplasty.

Feasibility of urodynamics in the elderly has been previously demonstrated (2). An unexpected result is the lower percentage of interpretable initial free uroflow (44\%) compared with the $60.8 \%$ for the group of 748 women under the age of 80 ; the percentages were similar in the 2 groups for both IF and FF2. Therefore, to be reliable, FF has to be repeated, making certain that the bladder is full enough and taking into account the difficulty for some patients to void in an "unfriendly" environment.

Analysis of filling cystometry shows an increased frequency of DO in this elderly population which is consistent with previous studies $(45 \%$ as opposed to $23.0 \%$ in the population less than 80 years old) but does not explain the complaint of urgency (70\%). Hashim and Abrams (16) have found that 44\% of women with urgency had DO; in our study 54\% of the women who complained of urgency had DO, which is slightly higher. This finding could be related to the decline in central nervous system cholinergic activity occurring with normal aging (17). In addition, we observed a high prevalence of DHIC (low detrusor pressure and high residual volume - 35\%). This specific association, first described by Resnick and Yalla (18), is characteristic of older patients and is a cause of urinary incontinence in the elderly. However, as this study was retrospective and as urodynamic studies are standardized in our laboratory, no provocative maneuver for DO was performed except for cough for quality control of pressure recordings.

Occurrence of RRCs confirmed the high prevalence of rhythmic rectal contractions in elderly patients $(31.8 \%$ as compared to $16.5 \%$ in the population less than 80 years old). We observed a strong association between RRCs, DO and neurological disease. Despite the small group studied Ozawa et al. have reported a similar result and concluded that 
RRCs may be regarded as one of the causes responsible for urinary difficulty in the elderly (19).

Maximum cystometric capacity was lower than the value reported by Pfisterer et al. (8); this difference could be the consequence of the high incidence of terminal DO in our population.

The mean MUCP value is the value expected for the age; bladder filled, the decrease of the MUCP value implies a lack of adaptation of the sphincter to bladder filling. However, approximately $50 \%$ of the population had at least one measurement (bladder empty or filled) $\leq 30 \mathrm{~cm} \mathrm{H}_{2} \mathrm{O}$.

The main urodynamic diagnosis was DO found in 45 women of whom 38 had suggested LUTS (urge or mixed incontinence, frequency). The second diagnosis, in frequency, was suggested ISD found in 25 women of whom 17 had LUTS (stress or mixed incontinence). That finding is probably the consequence of the association of ISD with a major urodynamic finding such as detrusor overactivity.

Sensitivity, specificity and predictive positive value of urgency for the detection of DO, and stress or mixed incontinence for the detection of ISD are good but not sufficient enough to eliminate urodynamics, mainly to avoid inappropriate new treatment in patients with failure of previous treatment (chemical or surgical). In other patients, who have a number of complaints and who experience great discomfort in daily life, urodynamics should enable the physician to choose the less invasive and quickly effective treatment.

A limitation of our study was that the physician performing the urodynamic investigation was not the physician who originally requested urodynamics. Therefore, our findings can only be considered as advice. A prospective study would be required for a better evaluation of the role played by urodynamics in the management of LUT dysfunction in this specific elderly population.

\section{CONCLUSION}

In this population of community-dwelling of elderly females referred by their physician in our urodynamics outpatient clinic, urodynamics primarily allows to find the causes of treatment failure. How- ever, the majority of the population complained of a decrease in their quality of life often due to LUTS which had developed over many years and asked for greater improvement.

The major complaint was incontinence, often associated with urgency which was the main symptom. The low success of FF at arrival suggests that anxiety and an "uncomfortable" environment might play a role in addition to the changes in rate of urine production with ageing. Prevalence of DO and DHIC, and occurrence of RRCs during cystometry increased compared to younger patients. DO and RRCs are frequently a concomitant finding of cystometry. A surprising result was the small group of patients for whom the proposed diagnosis was ISD alone.

\section{CONFLICT OF INTEREST}

None declared.

\section{REFERENCES}

1. Milsom I, Altman D, Lapitan MC, Nelson R, Sillén $\mathrm{U}$, Thom D. Epidemiology of urinary (UI) and faecal (FI) Incontinence and Pelvic organ Prolapse (POP). In Incontinence, 4th International Consultation on Incontinence. Abrams P, Cardozo L, Khoury S. (ed.), Health Publication Ltd. 2009; pp. 37-111.

2. Resnick NM, Yalla SV, Laurino E: The pathophysiology of urinary incontinence among institutionalized elderly persons. N Engl J Med. 1989; 320: 1-7.

3. Damián J, Martín-Moreno JM, Lobo F, Bonache J, Cerviño J, Redondo-Márquez L, Martínez-Agulló E: Prevalence of urinary incontinence among Spanish older people living at home. Eur Urol. 1998; 34: 3338.

4. Topinkova E: Aging, disability and frailty. Ann Nutr Metabol 2008; 52(suppl 1): 6-11.

5. Bergman H, Ferrucci L, Guralnik J, Hogan DB, Hummel S, Karunananthan S, et al.: Frailty: an emerging research and clinical paradigm--issues and controversies. J Gerontol A Biol Sci Med Sci. 2007; 62: 731-7.

6. van Iersel MB, Rikkert MG: Frailty criteria give heterogeneous results when applied in clinical practice. J Am Geriatr Soc. 2006; 54: 728-9.

7. Dubeau CE: The aging lower urinary tract. J Urol. 2006; 175: S11-5. 
8. Pfisterer MH, Griffiths DJ, Schaefer W, Resnick NM: The effect of age on lower urinary tract function: a study in women. J Am Geriatr Soc. 2006; 54: 40512.

9. Gomes CM, Arap S, Trigo-Rocha FE: Voiding dysfunction and urodynamic abnormalities in elderly patients. Rev Hosp Clin Fac Med Sao Paulo. 2004; 59: 206-15.

10. McGrother CW, Donaldson MM, Hayward T, Matthews R, Dallosso HM, Hyde C, et al.: Urinary storage symptoms and comorbidities: a prospective population cohort study in middle-aged and older women. Age Ageing. 2006; 35: 16-24.

11. Lin HH, Torng PL, Sheu BC, Shau WY, Huang SC: Urodynamically age-specific prevalence of urinary incontinence in women with urinary symptoms. Neurourol Urodyn. 2003; 22: 29-32.

12. Pfisterer MH, Griffiths DJ, Rosenberg L, Schaefer W, Resnick NM: The impact of detrusor overactivity on bladder function in younger and older women. J Urol. 2006; 175: 1777-83; discussion 1783.

13. Schäfer W, Abrams P, Liao L, Mattiasson A, Pesce F, Spangberg A, et al.: Good urodynamic practices: uroflowmetry, filling cystometry, and pressure-flow studies. Neurourol Urodyn. 2002; 21: 261-74.
14. Constantinou CE: Urethrometry: considerations of static, dynamic, and stability characteristics of the female urethra. Neurourol Urodyn 1988; 7: 521-39.

15. Hannestad YS, Rortveit G, Sandvik H, Hunskaar S, Norwegian EPINCONT study: Epidemiology of Incontinence in the County of Nord-Trøndelag: A community-based epidemiological survey of female urinary incontinence: the Norwegian EPINCONT study. Epidemiology of Incontinence in the County of Nord-Trøndelag. J Clin Epidemiol. 2000; 53: 1150-7.

16. Hashim H, Abrams $P$ : Is the bladder a reliable witness for predicting detrusor overactivity? J Urol. 2006; 175: 191-4; discussion 194-5.

17. Abrams P, Andersson KE: Muscarinic receptor antagonists for overactive bladder. BJU Int. 2007; 100: 987-1006.

18. Resnick NM, Yalla SV: Detrusor hyperactivity with impaired contractile function. An unrecognized but common cause of incontinence in elderly patients. JAMA. 1987; 257: 3076-81.

19. Ozawa H, Nagai A, Akiyama H, Ichikawa T, Akiyama M, Ono N, Oeda T, Kumon H, Ohmori H: Significance of rectal contractions during multichannel urodynamic study. Nippon Hinyokika Gakkai Zasshi. 1997; 88: 874-9.

\section{Correspondence address:}

Dr. Françoise A. Valentini

Université Pierre et Marie Curie (Paris 6)

4 Place Jussieu, 75005 Paris, France

Fax: + 33 14959-4697

E-mail: favalentini@gmail.com 